\title{
Experimental research on influence of functional parameters of combined installations designed at separating the impurities out of cereal seeds
}

\author{
Carmen Brăcăcescu ${ }^{1}$, Ioan Țenu ${ }^{2}$, Costin Mircea ${ }^{1}$, and George Bunduchi ${ }^{1}$ \\ ${ }^{1}$ National Institute of Research-Development for Machines and Installations designed to Agriculture \\ and Food Industry- INMA/ Bucharest, Romania; \\ 2"Ion Ionescu de la Brad" University of Agricultural Sciences and Veterinary Medicine of Iasi - \\ USAMV Iasi, Romania
}

\begin{abstract}
The paper presents the experimental installation, the methodology and measuring apparatus used for experimental research of qualitative indexes of impurities separation out of grain seeds for combined separating systems (according to specific weight and aerodynamic properties of seeds). The experimental installation used was composed of a gravimetric separator with mechanical shaker with unbalanced masses (mounted on the platform working surface) and an aspiration installation with fan. The experimental research has aimed at quantitative and qualitative influence on separation quality index of the following operating parameters: material flow rate of shaking separator, the air flow of aspiration installation, tilting work surface, work surface oscillation amplitude. Based on data obtained by measurements and qualitative indicators the separating process indexes have been determined, namely: degree of impurities separation, degree of good seeds loss, as well as, the separation quality index for different types of combinations of separation installation parameters.
\end{abstract}

\section{Introduction}

After the harvesting process, grain seeds cannot be used directly for different purposes (storage, consumption, industrialization, sowing, etc.) because they contain impurities of any kind (vegetal remains, foreign bodies, etc.) and injured products. Prior to receiving a particular destination, it is necessary and obligatory for the harvested products to undergo cleaning and sorting, called as primary processing operations.

The preparation of cereal seeds before processing them is a technological process, which requires technical equipment and combined installations types to eliminate foreign bodies existing in the mass of harvested seeds, whose construction depends on the different types of separation $[1,2,3,4]$.

\footnotetext{
* Corresponding author: carmenbraca@yahoo.com
} 
Thus, research in this area focused on the determination of the physico-chemical properties of the components of a seed mixture that influence the separation process, with the aim of eliminating as much as possible the impurities that reach the final stages of grain processing $[5,6,7]$

The modern conditioning units use installations for separation the impurities out of seed mass using a lot of separation principles, such as the differences between the volumetric weight and the air flow velocity of the components of the seed mixtures $[8,9,10]$.

In order to obtain efficient separation equipment with a low consumption of material, electricity and labor, it is necessary to have a thorough knowledge of the technology, constructive principles, operation and maintenance of these technical equipments.

The experimental model of gravimetric separator SG-01 is a innovative technical equipment representative for cereals seed cleaning, design, manufactured and testing by specialists from INMA Bucharest.

The paper presents the experimental combined separation installation, the methodology and measuring apparatus used for experimental research and some results of experimental research, in order to optimize the functional parameters.

\section{Material and method}

The experimental stand presented in the technological flow scheme in figure 1 , it is composed of the gravimetric separator (1) connected to a suction installation with air composed of fan (2) and the de-dusting cyclone (3).

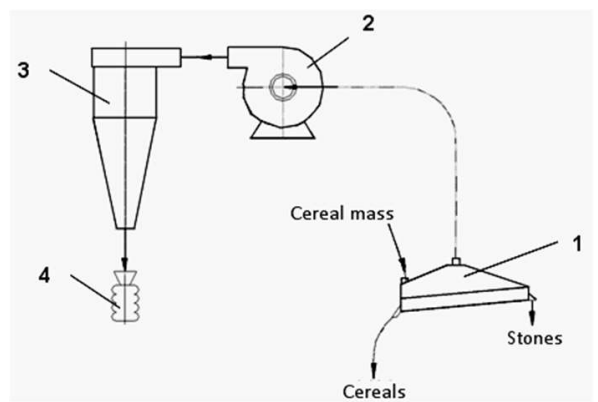

Fig. 1. Technological flow scheme of combined separation installation:

1 - gravimetric separator, 2 - fan, 3 - de-dusting cyclone, 4 - bags for dust and light impurities

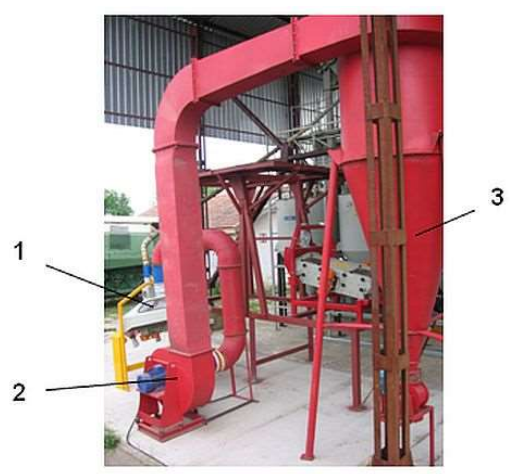

Fig.2. The stand (combined separation installation) used for experimental research

1 - gravimetric separator SG-01;2 - suction fan; 3 - de-dusting cyclone

The functional technical parameters of SG-01 are:

- capacity of processing, $\mathrm{t} / \mathrm{h}$ 
- cleaning process

- precleaning process

- necessary air flow rate, $\mathrm{m}^{3} / \mathrm{min}$.

- installed power, $\mathrm{kW}$

- frequency of oscillations, osc/min. $\min .2,5$

$\max .4$

150

$0,7(2 \times 0.35)$

960

The centrifugal drive force $F_{c f}$ of electrical motovibrators is regulate by adjusting the unbalanced masses, and the direction of oscillations can be adjusted by rotating the fixing support (figure 3).

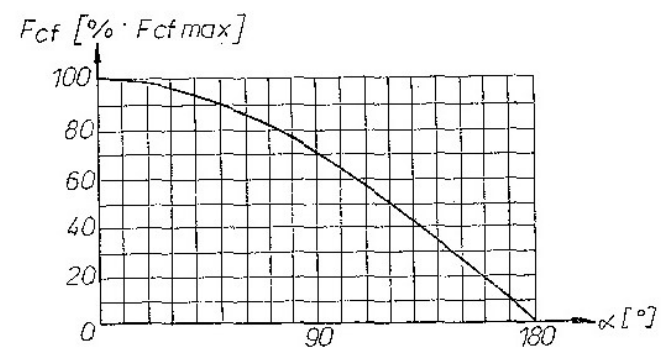

Fig. 3. Variation of centrifugal forces $F_{\text {cf }}$ of unbalance masses depending on the angle $\alpha$ of overlap of the non-balanced eccentric masses [11]

The vibration movement of the working platform is imprinted on the impurities or particles in contact with it after a trajectory allowed by the elastic support springs. Due to the combined effect of the vibrations of the working platform and the action of the air currents, the product mass is stratified on the sieve of working surface. Particles of impurities with a specific volumetric weight greater than grain seeds remain in contact with the vibrating working platform, while light foreign bodies are distributed in upper layers. Thus, under action of the aspirated air stream, the grain seeds are fluidized and float above the working surface, with which they do not come in constant contact, flowing on its inclined plane to the outlet connections located at the lower end of the gravimetric separator SG-01.

The material used at experimental researches was the cereals seed (mainly wheat). Specific measurement devices for acquisition or registration were used for experimental determinations [12] of the following parameters:

- masses of products (seeds and impurities);

- material supplying flow rate;

- velocity of air currents in the pipe of suction installation, using an anemometer model Testovent 4000;

- inclination angle of the working surface (vibrating frame);

- oscillation amplitude of the vibrating working frame, using an inductive displacement transducer, model W10-Hottinger;

- frequency of oscillation of the two motovibrators, after determination of rotation speed;

- energy consumption after determination of power consumption of motovibrators.

Also were determined the moisture content and hectolitric mass of product on entry and exit in the gravimetric separator SG-01 and at evacuation of impurities in the separation process.

The loss rate of good wheat seeds $\mathrm{C}_{\mathrm{ps}}$ is calculated with the relation [4]:

$$
C_{p s}=(m / M) \cdot 100 \quad[\%]
$$


where: $m$ is the mass of good wheat seeds which are found in the mass of eliminated impurities at the exit of SG-01, $\mathrm{kg}$; $M$ - mass of good wheat seeds at the entry into SG-01, $\mathrm{kg}$.

The separation quality index $E_{c s}$ was determined at a single pass of the product through the separator, this indicator representing the percent of impurities (foreign bodies) eliminated from the mass of processed wheat seeds and is determined with the relation [4]:

$$
E_{c s}=\left[\left(c_{c s i}-c_{c s e}\right) / c_{c s i}\right] \times 100 \quad[\%]
$$

where: $c_{c s i}$ is content impurities at the entrance of product in SG-01, \%

$c_{c s e}$ - content impurities at evacuation of product from SG-01, $\%$

Knowing the velocity $v(\mathrm{~m} / \mathrm{s})$ recorded at the anemometer model Testovent 4000 and the section $\mathrm{S}\left(\mathrm{m}^{2}\right)$ of the suction pipe, the air flow rate required for aspiration was determined with the relation:

$$
Q_{a}=3600 \cdot v \cdot S\left[\mathrm{~m}^{3} / \mathrm{h}\right]
$$

The electricity consumed by the two electric motovibrators $W$ is determinated by the relation:

$$
W=\left(P_{a} \cdot t\right) / 3600 \quad[\mathrm{kWh}]
$$

where: $P_{a}$ is the power absorbed, $\mathrm{kW}$, measured with the phase and frequency analyzer; $t$ operating time at tests, $\mathrm{s}$.

The capacity of processing $Q$ of the gravimetric separator SG-01 was calculated with the relation:

$$
Q=3600 \cdot m / t \quad[\mathrm{~kg} / \mathrm{h}]
$$

where: $m$ is the initial product mass, $\mathrm{kg} ; t$ - time required for experimental determination, $\mathrm{s}$.

\begin{tabular}{|c|c|c|c|}
\hline $\begin{array}{l}\text { Crt. } \\
\text { no. }\end{array}$ & Determined parameter & U.M. & $\begin{array}{l}\text { Parameter value } \\
\text { determined at tests }\end{array}$ \\
\hline 1. & 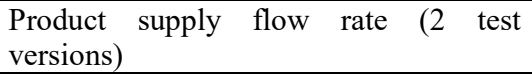 & $\mathrm{kg} / \mathrm{h}$ & $1000 ; 2000$ \\
\hline 2. & Duration of test versions & $\mathrm{s}$ & $2400 ; 1800$ \\
\hline 3. & $\begin{array}{l}\text { The initial quality indices of product at } \\
\text { the entry into SG-01: } \\
\text { - humidity; } \\
\text { - hectolitric mass; } \\
\text { - impurities }\end{array}$ & $\begin{array}{c}\% \\
\mathrm{~kg} / \mathrm{hl} \\
\% \\
\end{array}$ & $\begin{array}{c}11.93 \\
78.72 \\
2.41 ; 2.46 \\
\end{array}$ \\
\hline 4. & Loss rate of good wheat seeds $C_{p s}$ & $\%$ & $0.01 \div 0.95$ \\
\hline 5. & Separation quality index $E_{c s}$ & $\%$ & $\max .98 .57$ \\
\hline 6. & $\begin{array}{l}\text { The suction air flow rates of the } \\
\text { installation ( } 3 \text { test versions) }\end{array}$ & $\mathrm{m}^{3} / \mathrm{min}$. & $100 ; 125 ; 150$ \\
\hline 7. & $\begin{array}{l}\text { Air speed in the pipe at test versions of } \\
\text { suction air flow rates }\end{array}$ & $\mathrm{m} / \mathrm{s}$ & $17.36 ; 21.7 ; 26.04$ \\
\hline 8. & Power absorbed by motovibrators & $\mathrm{kW}$ & 0.7 \\
\hline 9. & Specific consumption of electricity & $\mathrm{kWh} / \mathrm{kg}$ & 0.00045 \\
\hline
\end{tabular}

In Table 1 and 2 are mentioned the values resulting from processing determined parameters.

Table 1. Functional operating parameters of SG-01 
Table 2. Some tests results for determination of optimal regime of the gravimetric separator SG-01

\begin{tabular}{|c|c|c|c|c|}
\hline $\begin{array}{c}\text { Wheat seed } \\
\text { feeding flow } \\
(\mathrm{kg} / \mathrm{h})\end{array}$ & $\begin{array}{l}\text { Air flow } \\
\left(\mathrm{m}^{3} / \mathrm{min}\right)\end{array}$ & $\begin{array}{c}\text { Angle of inclination } \\
\text { of working surface } \\
\left({ }^{\circ}\right)\end{array}$ & $\begin{array}{c}\text { Amplitude of } \\
\text { working surface } \\
(\mathrm{mm})\end{array}$ & $\begin{array}{l}\text { Quantity of impurities } \\
\text { eliminated at } 1000 \mathrm{~kg} \text { of } \\
\text { wheat seed processed }(\mathrm{kg})\end{array}$ \\
\hline \multirow{27}{*}{1500} & \multirow{9}{*}{100} & \multirow{3}{*}{5} & 1.5 & 35.5 \\
\hline & & & 2.0 & 38.6 \\
\hline & & & 2.5 & 41.2 \\
\hline & & \multirow{3}{*}{7.5} & 1.5 & 33.4 \\
\hline & & & 2.0 & \begin{tabular}{|l}
35.1 \\
\end{tabular} \\
\hline & & & 2.5 & 37.2 \\
\hline & & \multirow{3}{*}{10} & 1.5 & 31.6 \\
\hline & & & 2.0 & 33.7 \\
\hline & & & 2.5 & 34.8 \\
\hline & \multirow{9}{*}{125} & \multirow{3}{*}{5} & 1.5 & 26.3 \\
\hline & & & 2.0 & 29.2 \\
\hline & & & 2.5 & 33.1 \\
\hline & & \multirow{3}{*}{7.5} & 1.5 & 24.5 \\
\hline & & & 2.0 & 25.8 \\
\hline & & & 2.5 & 27.6 \\
\hline & & \multirow{3}{*}{10} & 1.5 & 21.3 \\
\hline & & & 2.0 & 22.8 \\
\hline & & & 2.5 & 23.6 \\
\hline & \multirow{9}{*}{150} & \multirow{3}{*}{5} & 1.5 & 29.7 \\
\hline & & & 2.0 & 21.4 \\
\hline & & & 2.5 & 23.8 \\
\hline & & \multirow{3}{*}{7.5} & 1.5 & 16.4 \\
\hline & & & 2.0 & 18.2 \\
\hline & & & 2.5 & 19.4 \\
\hline & & \multirow{3}{*}{10} & 1.5 & 15.6 \\
\hline & & & 2.0 & 16.8 \\
\hline & & & 2.5 & 17.9 \\
\hline \multirow{27}{*}{2000} & \multirow{9}{*}{100} & \multirow{3}{*}{5} & 1.5 & 37.6 \\
\hline & & & 2.0 & 40.2 \\
\hline & & & 2.5 & 43.4 \\
\hline & & \multirow{3}{*}{7.5} & 1.5 & 35.6 \\
\hline & & & 2.0 & 38.9 \\
\hline & & & 2.5 & 39.9 \\
\hline & & \multirow{3}{*}{10} & 1.5 & 33.3 \\
\hline & & & 2.0 & 35.4 \\
\hline & & & 2.5 & 36.7 \\
\hline & & \multirow{3}{*}{5} & 1.5 & 28.1 \\
\hline & & & 2.0 & 31.4 \\
\hline & & & 2.5 & 34.9 \\
\hline & & & 1.5 & 26.6 \\
\hline & 125 & 7.5 & 2.0 & 27.4 \\
\hline & & & 2.5 & 29.1 \\
\hline & & & 1.5 & 23.1 \\
\hline & & 10 & 2.0 & 25.1 \\
\hline & & & 2.5 & 26.0 \\
\hline & & & 1.5 & 21.2 \\
\hline & & 5 & 2.0 & 23.0 \\
\hline & & & 2.5 & 24.9 \\
\hline & & & 1.5 & 17.8 \\
\hline & 150 & 7.5 & 2.0 & 19.8 \\
\hline & & & 2.5 & 21.6 \\
\hline & & & 1.5 & 17.1 \\
\hline & & 10 & 2.0 & 18.3 \\
\hline & & & 2.5 & 19.2 \\
\hline
\end{tabular}




\section{Results and discussions}

After the analysis of the influence of constructive and functional parameters of the combined separation installation on the separation quality index $E_{c s}$ graphics were drawn expressing the following technological dependency of the indices values of the functional parameters (adjustment) of the gravimetric separator SG-01: the product feed rate of the gravimetric separator $Q g$, the air flow rate $Q a$ of the suction installation, the angle of inclination of the working surface $\alpha$ and the oscillation amplitude $A$ of the gravimetric separator working surface. In figures $4-6$ are presented, for illustration, some representative graphics.

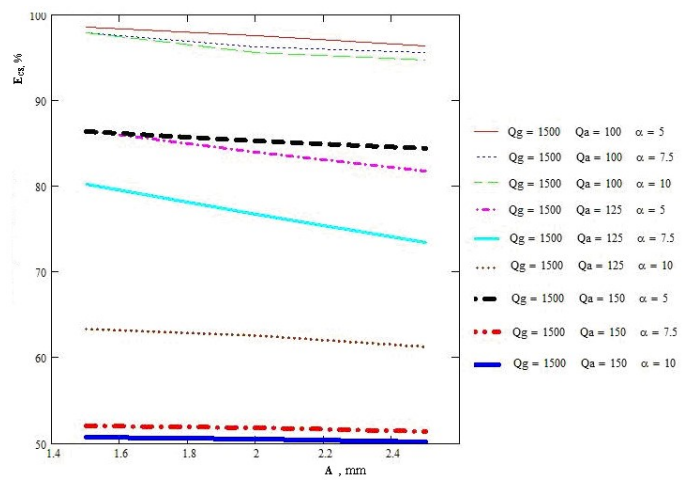

Fig. 4. The dependence of separation quality index $E_{C S}=f(A)$ for $Q_{g}=1500 \mathrm{~kg} / \mathrm{h}, Q a=100 \div 150 \mathrm{~m}^{3} / \mathrm{min}$ and $\alpha=5 \div 10^{\circ}$

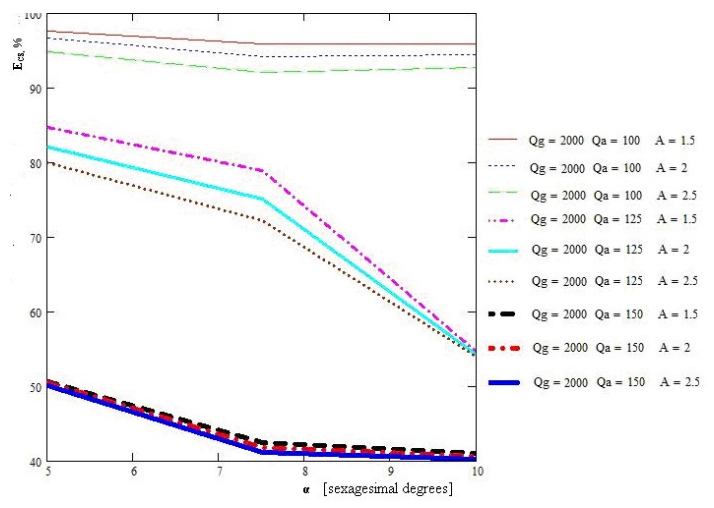

Fig. 5. The dependence of separation quality index $E_{C S}=f(\alpha)$ for $Q_{g}=2000 \mathrm{~kg} / \mathrm{h}, Q_{a}=100 \div 150 \mathrm{~m}^{3} / \mathrm{min}$ and $A=1,5 \div 2,5 \mathrm{~mm}$

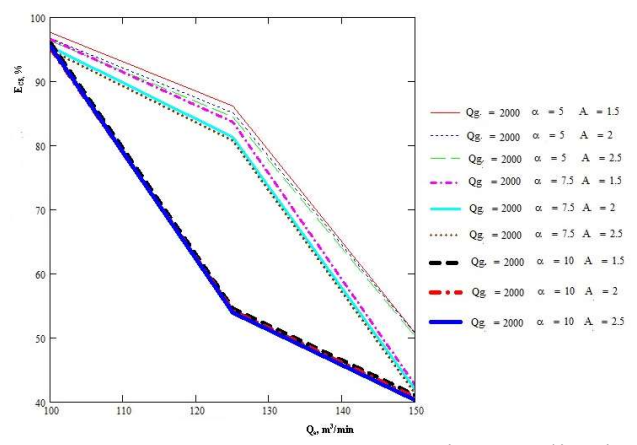

Fig. 6. The dependence of separation quality index $E_{C S}=f\left(Q_{a}\right)$ for $Q_{g}=2000 \mathrm{~kg} / \mathrm{h}, \alpha=5 \div 10^{\circ}$ and $A=1,5 \div 2,5 \mathrm{~mm}$ 
By applying linear regression method to determined experimental data processing, the separation quality index $E_{C S}$ is obtained expressed by the following relation [13]:

$$
E_{c S}\left(Q_{g}, Q_{a}, \alpha, A\right)=-0.15891 Q_{g}-0.848267 Q_{a}-3.256434 \alpha-2.736311 A+
$$
237.645462

The correlation between the experimental data and the data calculated in the experimental points with the regression given by the relation (6) is 0.932 .

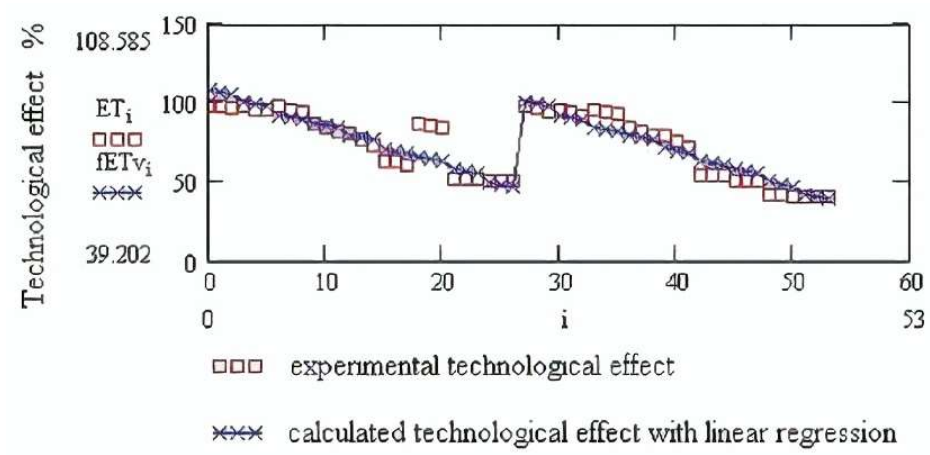

Fig.7. The separation quality index (technological effect) comparison of the experimental data with those obtained by linear regression

From the correlation of graphical representation in figure 4-7 with relation (6) result that the separation quality index $E_{C S}$ decreases with the increase of the supplying flow rate with product, of the working surface inclination angle, of the suction air flow rate and of the working surface amplitude.

It was noticeable that, by increasing of the cereal seeds rate flow through the impurities pipes are eliminated a part of good seeds and the loss rate of good wheat seeds is above normal limits.

\section{Conclusions}

The working process of the gravimetric separator SG-01 achieves a high precleaning of the product (wheat seeds). The technological parameters obtained during experimental tests depend on: the regulation of the working vibration platform (oscillations amplitude and angle of inclination), the suction air flow as well as the wheat seed feeding flow.

By equipping with a pair of electric motovibrators, the oscillating movement induced by them allow to the gravimetric separator SG-01 a high output capacity and an increased separating efficiency.

The experimental measurements revealed the following conclusions:

1. the ascending airflow generated by the suction installation favors the stratification of seeds mixture uniform dimensionally with different specific volumetric weights, their movement on the working surface of the gravimetric separator being possible even at the minimum amplitudes of oscillation;

2. by increasing the air flow rate between $100 \div 150 \mathrm{~m}^{3} / \mathrm{min}$ the combined separating installations performances are enhanced, through a better product layer structure achieved depending on the specific volumetric weight of grain seeds and other impurities; 
3. the oscillations amplitude influence upon the working regime, establishing as optimum values between $2 \div 2.5 \mathrm{~mm}$;

4. by increasing the tilting angle of the working surface between $5 \div 10^{\circ}$ the wheat seeds quantity eliminated through the joint of impurities is reduced. Also, over $10^{\circ}$ the gravimetric separator SG-01 have diminished their performances;

5. the separation quality index resulted at a single passage of the product was of $98.57 \%$ for big foreign bodies eliminated, $91.35 \%$ for small foreign bodies eliminated, $95.3 \%$ for light foreign bodies eliminated.

Therefore, the results of experimental researches obtained by direct measurement or determined by calculation show that the combined installation consisting of gravimetric separator model SG-01 and the suction installation comply with the requirements in terms of security and functioning mode offering multiple possibilities for adjustment and servicing.

\section{Acknowledgements}

This work was supported by:

- a grant of the Romanian Research and Innovation Ministry, through Programme 1 Development of the national research-development system, subprogramme 1.2 Institutional performance - Projects for financing excellence in RDI, contract no. 16PFE.

- a grant of the Romanian Research and Innovation Ministry CCDI - UEFISCDI, Project INNOVATIVE TECHNOLOGIES FOR IRRIGATION OF AGRICULTURAL CROPS IN ARID, SEMIARID AND SUBHUMID-DRY CLIMATE, project number PN-III-P1-1.2PCCDI-2017-0254, Contract no. 27PCCDI / 2018, within PNCDI III.

\section{References}

1. T. Căsăndroiu, Primary processing and agricultural products storing, lithographed course, Politehnica University of Bucharest (1993)

2. I. Danciu, Cereals cleaning, University "Lucian Blaga" Publishing House, Sibiu, (2001)

3. Fl. Rus, Separation operations in the food industry, Publishing Transylvania University of Braşov (2001)

4. V.F. Didyh, Improving the efficiency of drying agricultural plant materials: monograph, Lutsk pp. 75-101 (2002)

5. A.D. Zewdu, Aerodynamic properties of the grain and straw material, Biosystems Engineering Journal, 98, pp. $304-309$ (2007)

6. Z. Jing Z, Design of New Grain Threshing Cleaning Device. Journal of London University, 1, 17, London/UK (2013);

7. C. Brăcăcescu, Sorică C., D. Manea, Yao Guanxin, G.A. Constantin - Theoretical contributions to the drive of cereal cleaning technical equipment endowed with non balanced vibration generating systems, INMATEH - Agricultural Engineering, vol. 42, no. 1 / 2014, pp. 69 - 74, (2014)

8. A.V.Nesterenko, S.M.Leshchenko, O.M.Vasylkovskyi, D.I.Petrenko, Analytical assessment of the pneumatic separation quality in the process of grain multilayer feeding. INMATEH Agricultural Engineering, 53, No. 3, pp.65-70, Bucharest/Romania (2017),

9. I. Costin, Miller's Book, Technical Publishing House, Bucharest, Romania (1999)

10. Chr. Geankoplis,Transport processes and separation process principles, Prentice Hall PTR, Fourth Edition, 14, pp.903-944, (2003) 
11. O. Vasylkovskyi, K. Vasylkovska, S. Moroz, M. Sviren, L. Storozhyk, The influence of basic parameters of separating conveyor operation on grain cleaning quality, INMATEH- Agricultural Engineering, 57, no.1/2019, pp 63-70, (2019),

12. V. Damian, Manual of the Food Industry Engineer, 28-Measuring and control devices, control and adjustment, pp.1234-1262, Technical publishing house, Bucharest (1998)

13. C. Brăcăcescu, Theoretical and experimental researches regarding the optimization of working processes of gravimetrical separators aimed at cereals impurities, $\mathrm{PhD}$ thesis (Transilvania University of Brasov, 2011) 